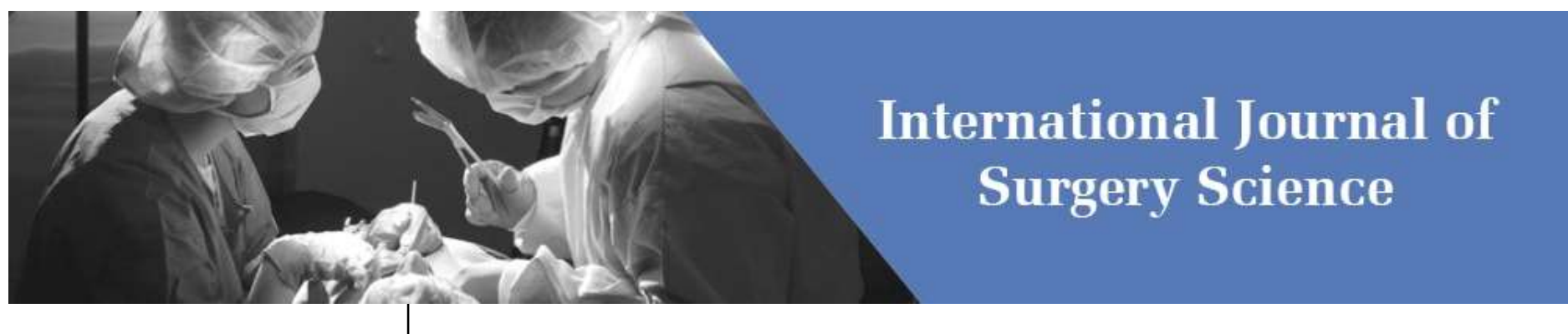

E-ISSN: 2616-3470

P-ISSN: 2616-3462

(C) Surgery Science www.surgeryscience.com

2021; 5(4): 74-75

Received: 21-07-2021

Accepted: 08-09-2021

Dr. Girish Pandey

Associate Professor, Department of

Surgery, Heritage Institute of

Medical Sciences, Varanasi, Uttar

Pradesh, India

\section{A prospective study comparing routine subhepatic drain vs no drain in patients undergoing simple elective laparoscopic cholecystectomy}

\section{Dr. Girish Pandey}

DOI: https://doi.org/10.33545/surgery.2021.v5.i4b.763

\section{Abstract}

Background: Cholelithiasis is one of the major causes of morbidity with prevalence rate of $10-20 \%$. Cholecystectomy is the mainstay of treatment of gall stone disease. Open cholecystectomy was the traditional method of treatment. It has now largely been replaced by laparoscopic cholecystectomy. To put a subhepatic drain in laparoscopic cholecystectomy patients routinely is a big question. Our aim is to find out whether routine use of drains in all patients undergoing elective laparoscopic cholecystectomy to be recommended.

Methods: A prospective study of 100 cases was carried out in department of surgery in Heritage Institute of Medical Sciences, Varanasi between January 2020 to august 2021 with the aim of making comparisons between drained \& non drained laparoscopic cholecystectomy patients. The patients were randomly assigned into two groups. Group A consists of patients with subhepatic drain and in group B no drains were kept.

Results: Patients with subhepatic drains have similar pain as compared to non-drain group in immediate post-operative period but had more pain, discomfort, longer hospital stay and required slightly long time for complete wound healing especially of drain port wound and full recovery.

Conclusion: Routine subhepatic drain after every case of laparoscopic cholecystectomy is not necessary especially in clear, uncomplicated cases.

Keywords: Cholecystectomy, gall stone disease, Laparoscopic cholecystectomy

\section{Introduction}

Cholelithiasis is one of the most prevalent surgical problems. Laparoscopic cholecystectomy is one of the most common surgical procedure being performed now a days. After taking out specimen, biggest question that comes to the mind of every surgeon is whether to put drain in subhepatic space or not? It is believed that any collection will come out via drain and patient will be saved from complications. Our study was done with the aim of comparison between use of routine drains to no drain in affecting surgical outcome in simple, uncomplicated, elective laparoscopic cholecystectomy.

\section{Methods}

A prospective study of 100 patients was conducted in Dept. of Surgery at Heritage Institute of Medical Sciences Varanasi between January 2020 to august 2021.

All patients were suffering from cholelithiasis without acute attack in preceding three months. Certain exclusion criteria were also used.

\section{Exclusion criteria}

Acute cholecystitis $\quad$ - $\quad$ choledocholithiasis

Acute pancreatitis _ $\quad$ - $\quad$ previous upper abdominal surgery

Patients were randomly divided into two groups. In Group A, subhepatic drain was kept routinely and group B, where no drain was kept. An informed consent was taken before and patients were explained about merits and demerits of subhepatic drainage.

All patients were admitted and detailed history, proper clinical examination and investigations like CBC, blood sugar, RFT, LFT, Ultrasound abdomen was done before subjecting patients for laparoscopic cholecystectomy.
Corresponding Author: Dr. Girish Pandey Associate Professor, Department of Surgery, Heritage Institute of Medical Sciences, Varanasi, Uttar Pradesh, India 
All patints were operated under GA with Endotracheal insufflation. Antibiotic prophylaxis given using inj cefuroxime at induction of anaesthesia. It was continued postoperatively also.

Operative findings were noted like- OT time (first port to last port), gall bladder size, adhesions, no. of stones, complications, conversions, subhepatic drainage kept or not. Complete haemostasis was achieved in all. Subhepatic removal suction drain no.14 was kept in group A and no drains in group B. Both groups were compared regarding postoperative pain, the time needed for surgery, postoperative hospital stay, postoperative collection in subhepatic space and incidence of postoperative complications. Severity of pain was recorded using visual analog scale and verbal response scale. Inj Diclofenac was used as analgesic supplemented with inj tramadol.

Patients were discharged once fully ambulatory and started tolerating well. Post-op USG was done before discharge in both groups to see for any collection \& measurement of its volume if present. Drains were removed when output was less than 20 $\mathrm{ml} /$ day. Skin sutures were removed after 7 post op days. USG abdomen was done again to see for any collection \& measurement of its volume on that day. Patient's were then followed up after one month. Patients were also asked to report immediately in case of any problem.

We wanted to compare advantages of drains with disadvantages.

\section{Results}

Majority of patients were females $(78.2 \%)$. There were 32 females \& 18 males in group A with drain while 35 females \& 15 males in group B.

Table 1: Sex distribution

\begin{tabular}{|c|c|c|c|c|}
\hline Sex & Group A & Percentage & Group B & Percentage \\
\hline Males & 18 & 36 & 15 & 30 \\
\hline Females & 32 & 64 & 35 & 70 \\
\hline Total & 50 & 100 & 50 & 100 \\
\hline
\end{tabular}

Age of patients varied from 18 years to 70 years \& majority belonged to age group 35-60.

Table 2: Age Distribution

\begin{tabular}{|c|c|c|c|c|}
\hline Age Group & Group A & Percentage & Group B & Percentage \\
\hline$<20 \mathrm{yr}$ & 2 & 4 & 3 & 6 \\
\hline $21-40 \mathrm{yr}$ & 14 & 28 & 16 & 32 \\
\hline $41-60 \mathrm{yr}$ & 32 & 64 & 28 & 56 \\
\hline $61-70$ & 2 & 4 & 3 & 6 \\
\hline Total & 50 & 100 & 50 & 100 \\
\hline
\end{tabular}

Table 3: Duration of Surgery

\begin{tabular}{|c|c|c|}
\hline Operative time & Group A (with drain) & Group B (no drain) \\
\hline$<40 \mathrm{~min}$ & 12 & 10 \\
\hline $41-50 \mathrm{~min}$ & 26 & 24 \\
\hline $51-60 \mathrm{~min}$ & 13 & 10 \\
\hline$>60 \mathrm{~min}$ & 3 & 3 \\
\hline
\end{tabular}

The patients who underwent lap chole with drain (group A) had similar pain as compared to non-drain (group B) in immediate postoperative period but post -operative pain and discomfort was slightly more on post-op days $2 \& 3$ in drain group than in non-drain group.

Postoperative stay was shorter in non -drain group than in drain group. The mean period of hospital stay was 2-3 days in nondrain group and $>3$ days in drain group. Few patients in drain group required even 4-5 days stay because drain output was more than our criteria of $20 \mathrm{ml} /$ day for removal.
There were no deaths, no patient required reoperation or drainage of subhepatic collection. Wound infections occurred in six patients with drain and five patients without drain. Most infections were Staphylococcal and were managed by dressings and oral antibiotics.

There was no statistical difference in rate of pain, nausea \& vomiting, post-operative pulmonary complications, wound infection between both groups. Statistical analysis by method of Odds ratio supported our findings.

Patients whose drains were removed on day $3 \& 4$ took slightly more time as although other ports healed but drain ports required 3-4 days more for complete healing than non-drain group were in majority all stitches were removed on day 8 and wounds were left open without any dressing.

\section{Discussion}

After laparoscopic cholecystectomy which is one of the commonest surgical procedure now a days, to put a drain routinely in subhepatic space in all patients is a big question, especially when surgical procedure is clean without any spillage and with complete haemostasis.

The main reason for putting drain is fear of bile leakage leading to subdiaphragmatic/subhepatic collection, fever, pulmonary complications, sometimes biliary peritonitis. Bile not always leaks from clipped cystic duct but also from aberrant cystic duct or sometimes from liver bed itself. Sometimes blood also collects there. Collected Bile/blood can come out via drain.

Also it is believed that there are decreased chances of shoulder pain due to drainage of $\mathrm{Co} 2$ in drain patients.

There are certain disadvantages of drain also like- Increased post-operative pain \& discomfort due to drain pipe, Increased cost especially if closed vacuum suction drains used. Sometimes drains give false sense of security as they get blocked by omentum and collection continues to accumulates inside. Sometimes, drain itself can act as foreign body and stimulate formation of fluid, increased chances of infection also seen.

Advantages of not putting drain are- decreased hospital stay, increased patient comfort, less incidence of wound complications. Even if some collection occurs, it can be easily handled by ultrasound guided percutaneous methods.

\section{Conclusion}

Routine subhepatic drain after laparoscopic cholecystectomy is not necessary in all clear, uncomplicated, elective cases of cholelithiasis with nicely delinated anatomy.

However, in cases where surgery has been difficult, unclear anatomy, bile or stone spillage, difficulty in haemostasis, it is reasonable to put a drain especially closed type of vacuum suction drain via most lateral axillary port.

\section{References}

1. Nomdeden J, Salvadar J. Systematic placement of drains in laparoscopic cholecystectomy. A prospective study. Revista de la sociedad valenciane digestive 1996;15(4):299-300.

2. Mrozowicz A, Rusinski P, Polkowski WP. Routine drainage of subhepatic area after lap chole. A prospective, controlled study with random patient selection.polski Przeglad Chirurgiczny 2006;78(5):597-609.

3. Hawash A, Brown E. The effect of drains in lap cholcystectomy, Jr of Laparoendosurg 1994;4(6):393-398.

4. McCormack TT, Abel PD, Collins CD. Abdominal drainage following cholcystectomy: high, low or no suction? Ann R Coll Surg England 1983;65:326-328.

5. Goodall RG, ParkM. Simple elective cholcystectomy: To drain or not. Am Jr of Surgery 1990;159(2):241-245.

6. RT Lewis et al. Am Jr of surgery 1990. 